\title{
Current perspectives on diagnosis and management of sternal wound infections
}

This article was published in the following Dove Press journal: Infection and Drug Resistance

\section{Erlangga Yusuf' \\ Monica Chan² \\ Nora Renz ${ }^{3}$ \\ Andrej Trampuz ${ }^{3}$}

'Department of Medical Microbiology, Antwerp University Hospital (UZA), University of Antwerp, Antwerp, Belgium; ' ${ }^{2}$ Department of Infectious Diseases, Tan Tock Seng Hospital, Singapore; ${ }^{3}$ Charité Universitätsmedizin Berlin, corporate member of Freie Universität Berlin, Humboldt-Universität zu Berlin, and Berlin Institute of Health, Center for Musculoskeletal Surgery (CMSC), Berlin, Germany

\section{Video abstract}

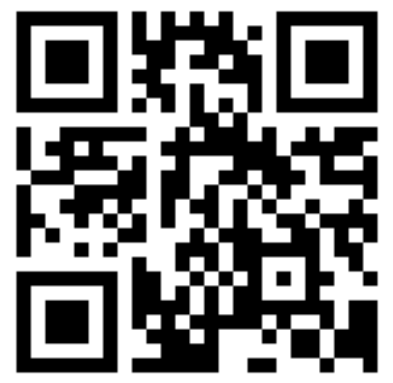

Point your SmartPhone at the code above. If you have a QR code reader the video abstract will appear. Or use: http://youtu.be/45ThhgGJVeA

Correspondence: Erlangga Yusuf Department of Microbiology, Antwerp University Hospital (UZA), University of Antwerp, Wilrijkstraat 10, Antwerp 2650, Edegem, Belgium

Tel +3247490 I232

Email angga.yusuf@gmail.com

\begin{abstract}
Deep sternal wound infection (DSWI), also known as mediastinitis, is a serious and potentially fatal condition. The diagnosis and treatment of DSWI are challenging. In this current narrative review, the epidemiology, risk factors, diagnosis, and surgical and antimicrobial management of DSWI are discussed. Ideally, the management of DSWI requires early and sufficient surgical debridement and appropriate antibiotic therapy. When foreign material is present, biofilm-active antibiotic therapy is also needed. Because DSWI is often complex, the management requires the involvement of a multidisciplinary team consisting of cardiothoracic surgeons, plastic surgeons, intensivists, infectious disease specialists, and clinical microbiologists.
\end{abstract}

Keywords: deep sternal wound infection, diagnosis, antibiotic, surgical treatment

\section{Introduction}

Deep sternal wound infection (DSWI), also known as post-sternotomy infection of the mediastinal space (mediastinitis) (Figure 1), is a serious and potentially fatal complication of median sternotomy, a procedure performed mainly for cardiac surgeries. ${ }^{1,2}$ Rarely, DSWI can occur also by hematogenous route (mainly in children) and by contiguous extension from an adjacent infectious process (e.g., arthritis). ${ }^{3}$ The mediastinal space is the area between sternum and the vertebral column that contains the heart and its large vessels, esophagus, trachea, and other structures and tissues such as lymph nodes and thymus. DSWI can involve the mediastinum, bone or cartilage, and infections beneath the subcutaneous tissue. ${ }^{4}$ Noninfectious causes of sternum osteomyelitis usually involve the sternoclavicular or sternocostal joints and is related to an immunological process rather than infection, typically presenting as systemic or multifocal inflammation (e.g., SAPHO syndrome, vasculitis, and chronic recurrent multifocal osteomyelitis).

In this current narrative review, the epidemiology, risk factors, diagnosis, and surgical and antimicrobial management of DSWI are discussed. Ideally, the management of DSWI requires early and sufficient surgical debridement, combined with bactericidal antibiotic therapy. In case of presence of foreign material, biofilm-active antibiotic therapy is also needed. Due to complex situation and difficulties in making the diagnosis, the management of such complications requires the involvement of a multidisciplinary team consisting of cardiothoracic surgeons, plastic surgeons, intensivists, infectious disease specialists, and clinical microbiologists.

\section{Epidemiology, risk factors, and classification}

The incidence of DSWI varies between centers, countries, and year of publication, but most studies reported incidence between $0.5 \%$ and $2 \% .^{2,5-7}$ The incidence is quite low, 
but DSWI results in devastating consequences, with reported increased 1-year mortality of $10.7 \%$ (compared with $2.5 \%$ in patients without DSWI), longer mean hospital stay of 33 days versus 9 days, and the estimated higher cost compared with patients without DSWI (US\$211,478 vs \$82,089). ${ }^{8}$

Risk factors for DSWI can be broadly grouped into patient related, intraoperative, and postoperative factors. Patient-associated risk factors are older age, obesity, smoking, and presence of comorbidities such as diabetes mellitus and chronic lung disease. ${ }^{4,7,9,10}$ A recent case control study showed that novel finding of chronic infections (human immunodeficiency virus, hepatitis B virus, hepatitis $\mathrm{C}$ virus, or bacterial infection longer than 4 weeks, or on antibiotics at surgery) was another risk factor for DSWI. ${ }^{11}$ Concomitant

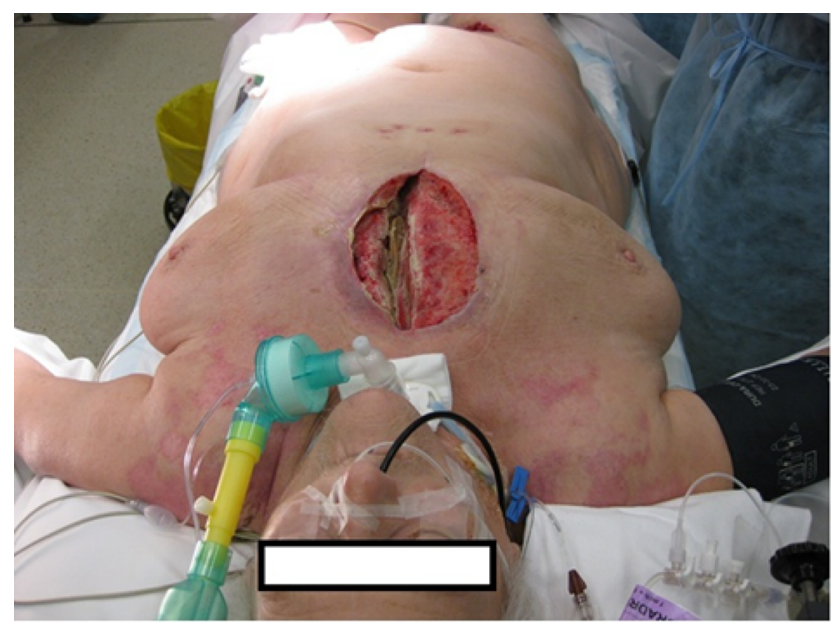

Figure I Deep sternal wound infection in a patient. coronary artery bypass grafting with valve or aortic surgery, long operation time, and bilateral use of internal mammary arteries are among surgery-associated risk factors. ${ }^{4,7,12}$ Reported postoperative risk factors are prolonged ventilator support and inotropic support. ${ }^{7,13}$

Based on the number of risk factors and time to presentation after surgery, El Oakley and Wright classified DSWI into five classes (Table 1). ${ }^{14}$ Such a classification can be used for comparison between different management protocols and used in research to refine the management of DSWI. When sternal wound infection is classified according to the anatomy of infected tissue, DSWI should be differentiated from superficial wound infection (Table 2). Whereas superficial infection involves only skin and subcutaneous tissue (type 1), deep infection extends below the fascia without involvement of the bone or retrosternal tissue (type 2A); involves retrosternal tissue (type $2 \mathrm{~B}$ ), bone and retrosternal tissue (type 2C); or causes frank osteitis (type 2D). ${ }^{15,16}$

\section{Diagnosis}

The diagnosis of DSWI is often difficult to make. It is based on the combination between clinical symptoms and signs, and laboratory and radiological findings. According to the Centers for Disease Control and Prevention (CDC), DSWI must meet at least one of the following three criteria: 1) organism(s) are identified from mediastinal tissue or fluid by a culture- or nonculture-based microbiologic testing method that is performed for the purposes of clinical diagnosis or treatment (not for surveillance purpose); 2) evidence of

Table I El Oakley and Wright classification of deep sternal wound infection

\begin{tabular}{llll}
\hline Type & Presentation after operation & Number of risk factors & Additional criteria \\
\hline I & Within 2 weeks & 0 & - \\
II & 2-6 weeks & 0 & - \\
IIla & Within 2 weeks & $\geq I$ & - \\
IIIb & 2-6 weeks & $\geq I$ & - \\
IVa & Type I, II, or III & - & One failed therapeutic trial \\
IVb & Type I, II, or III & - & Two or more failed therapeutic trials \\
V & $>6$ weeks & - & -
\end{tabular}

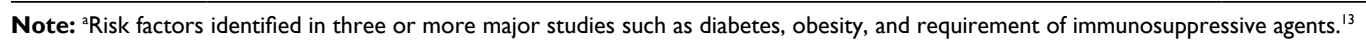

Table 2 Terminology of deep sternal wound infection based on involved anatomic layer

\begin{tabular}{lll}
\hline Entity & Type & Involvement \\
\hline Superficial sternal infection (above the fascia) & Type I & Skin and subcutaneous tissue only \\
Deep sternal infection (below the fascia) & Type 2A & Without involvement of the bone or retrosternal tissue \\
& Type 2B & Retrosternal tissue \\
& Type 2C & Bone and retrosternal tissue \\
& Type 2D & Frank osteitis \\
\hline
\end{tabular}

Note: Data from Tegnell et al' ${ }^{15}$ and Horan et al. ${ }^{16}$ 
mediastinitis on gross anatomic or histopathologic exam and 3) patient has at least one of the following signs or symptoms: fever $\left(>38.0^{\circ} \mathrm{C}\right)$, chest pain, or sternal instability, and at least one of the following: purulent drainage from mediastinal area or mediastinal widening on imaging test. ${ }^{17}$ For patients $<1$ year old, the diagnosis of mediastinitis can be made if the patient has at least one of the following signs or symptoms: fever $\left(>38.0^{\circ} \mathrm{C}\right)$, hypothermia $\left(<36.0^{\circ} \mathrm{C}\right)$, no other recognized cause of apnea or bradycardia, or sternal instability. In these patients, the sign should be accompanied with purulent drainage from mediastinal area or mediastinal widening on imaging test. ${ }^{17}$

Besides the signs and symptoms mentioned by CDC, other clinical signs suggestive of early DSWI include surrounding cellulitis and wound dehiscence, sometimes accompanied by systemic inflammation with tachycardia and hypotension. ${ }^{18}$ These signs and symptoms typically present within 30 days of cardiac surgery. ${ }^{19}$ In our previous study, wound dehiscence ( $75 \%$ of the patients), wound discharge $(69 \%)$, and sternal instability $(51 \%)$ were the most common signs found with fever, occurring in $29 \%$ of the patients. ${ }^{20}$ In contrast, chronic DSWI may present with delayed or poor wound healing or even a sternocutaneous fistula. ${ }^{18}$

The clinical diagnosis is supported by laboratory and radiology findings. White blood cell counts, C-reactive protein (CRP), and erythrocyte sedimentation rate are common screening tests in patients with suspected DSWI; however, neither tests are specific nor particularly sensitive, especially during the postoperative period. ${ }^{21}$ Due to the high frequency of bacteremia, ranging from $18 \%$ to $57 \%$, in patients with acute postoperative mediastinitis, blood cultures should always be performed. Positive blood cultures, particularly for Staphylococcus aureus, may be helpful in identifying acute sternal osteomyelitis as the source of infection. ${ }^{22,23}$

Radiographic abnormalities supporting the diagnosis of acute mediastinitis include widening of the mediastinum, mediastinal air-fluid levels, pneumomediastinum, and pleural effusion on chest radiograph. ${ }^{24}$ In chronic osteomyelitis, displaced sternal wires, sternal dehiscence, and rarely, osteolysis may be detectable. The extent of mediastinal infection, however, cannot be made based on chest radiography alone. Computed tomography (CT) is useful to assess the extent of mediastinal disease. Common CT findings include fluid collections, abscess formation, air pockets, extension into adjacent joints, pleural and pericardial fluid, adenopathy, and parenchymal and sternal abnormalities. ${ }^{24,25}$ Similarly, magnetic resonance imaging (MRI) can detect structural abnormalities including early detection of osteomyelitis, as evidenced by bone marrow hypointense signals on T1-weighted images and hyperintense signals on T2-weighted images. Percutaneous aspiration of focal collections can guide microbiological diagnosis. Despite the high sensitivity of CT and MRI, postoperative fluid or air pockets can persist for several days to weeks, thus lowering the specificity of findings, particularly in the early postoperative period. However, normal findings would rapidly exclude any significant retrosternal pathology abnormalities..$^{20,21}$ Potentially, positron emission tomography combined with CT imaging is useful in localizing the disease sites to guide adequate debridement. Also, it can be used to monitor the evolution of DSWI. ${ }^{26}$

\section{Microbiology}

Knowledge on microorganism that can cause DSWI is important in determining the choice of antimicrobials for prophylaxis, empiric, and targeted treatment. Cultures from tissue samples obtained during surgical debridement were positive in $62 \%$ of patients, and among them, most (94\%) were monomicrobial. ${ }^{20}$ Gram-positive bacteria were the most common microorganisms ( $89 \%$ of all pathogens), followed by Gram-negative rods in 10\%. Coagulase-negative staphylococci were the most common microorganism (56\% among all Gram-positive organisms). S. aureus were found in $24 \%$ of Gram-positive organisms. Although the numbers and percentages are different in various studies, the findings that coagulase-negative staphylococci and $S$. aureus are the most common pathogens are consistent throughout the years..$^{20,27-30}$

A study using superficial swab culture found $75 \%$ positive cultures of patients with probable DSWI ${ }^{31}$ Although superficial swab might enable early diagnosis of DSWI, the risk for false positive findings is high since the skin is colonized by microorganisms that can also be responsible for DSWI. Since the finding of microorganism in superficial swab may trigger the diagnosis of DSWI and can lead to unnecessary treatment, the superficial swab culture should not be performed.

Interestingly, when infection persisted after surgical and antibiotic treatments, Gram-negative rods, especially Enterobacteriaceae, were found more often and the proportion of Gram-positive cocci decreased. ${ }^{20}$ Perhaps, this is caused due to the selection of antibiotics targeted Grampositive only, but it is also possible that the Gram-negative were not detected earlier. DSWI with Gram-negative rods is also associated with worse prognosis than DSWI with Gram-positive microorganisms. Charbonneau et al showed that 30-day hospital mortality was significantly higher with Gram-negative rods than with Gram-positive bacteria (31.9\% versus $17.0 \% ; p=0.004) .{ }^{29}$ Gram-negative rods were found 
mostly together with other bacteria (polymicrobial), especially with other Gram-negative rods. ${ }^{20,29}$ Non-fermenters such as Pseudomonas aeruginosa and yeasts are found less common in DSWI, but their frequency increases with the number of surgical revisions. ${ }^{20,29,32}$

\section{Surgical management}

Although several surgical options exist in current practice, there is a lack of consensus on optimal surgical management. ${ }^{33}$ Traditional surgical treatment modalities introduced in the 1960s involved wound debridement, primary sternal closure, and mediastinal catheter irrigation with antibiotic or antiseptic solution. ${ }^{33,34}$ Due to unsatisfactory treatment results and advances in surgical techniques, alternative surgical concepts were evaluated including surgical revision with debridement, open dressing, and secondary closure, with or without reconstruction with vascularized soft tissue flaps such as greater omentum or pectoral muscles. ${ }^{35,36}$

Aside from flap coverage, another option for sternal wound closure is negative pressure wound therapy (NPWT; also known as vacuum-assisted closure [VAC]). VAC systems were introduced in the late 1990s as a novel therapeutic wound healing method. The continual drainage of bacteria, debris, and exudates by negative wound pressure enhances microcirculation and accelerates tissue granulation. ${ }^{37}$ The mass filling effect of the foam stabilizes and approximates the sternal wound edge. Prompted by its increasing use, several studies have found the clinical effect of VAC to be comparable to traditional closed drainage or open packing, with improvement in sternal wound healing, reinfection rates, length of ICU stay, and possibly mortality. ${ }^{38,39}$ However, VAC system itself can be a reservoir for microorganisms and may lead to emergence of multiresistant microorganisms, such as Gram-negative bacilli and yeasts (Candida spp.). In a previous study, 68 foams were cultured after sonication procedure, and in $65(97 \%)$ foams, at least one bacterial species was found. The bacterial load was ranging from $10^{4}$ to $10^{6} \mathrm{CFU} / \mathrm{mL} .{ }^{40}$

The interval to wound closure remains unclear. Variations in clinical practice include from early closure within 48 hours to multiple debridements and until bacteriology samples are negative. Delayed closure is associated with the risk of secondary infection, possibly due to the increased opportunity for bacterial inoculation and multiplication, from either repeated interventions or exposure of the open wound to the environment. The emergence of polymicrobial, Gramnegative, and fungal organism infection in delayed sternal closure is concerning for the development of antimicrobial resistance and need for broad-spectrum antibiotics. Although early closure of the chest may not be possible for all patients, for example in patients requiring extensive debridement, poor pulmonary or cardiac reserve, early sternal closure after debridement is a surgical strategy which requires further investigation in selected patients. Therefore, NPWT should be used as short as possible and plastic coverage performed as early as possible. ${ }^{41}$ In combination with highly active antibiotic therapy, the risk of mediastinitis after wound closure and failure of the flap is minimal.

\section{Antimicrobial prophylaxis}

Analogous to other surgical site infections, ${ }^{42}$ recommendations for the prevention of DSWI include preoperative prophylactic antibiotics and other additional preoperative measures such as nasal disinfectants and bathing. The guidelines from the Society of Thoracic Surgeons Workforce on EvidenceBased Medicine recommended the use of an intravenous cephalosporin (cefazolin or cefuroxime) within 60 minutes before the skin incision, and to be continued for no longer than 48 hours. ${ }^{43,44}$ Redosing is needed when procedures are longer than 4 hours. As an alternative, vancomycin can be used for patients with documented previous Type 1 allergic reactions (urticaria, eczema, conjunctivitis, angioedema, or anaphylaxis, occurring between 30 and 60 minutes or within minutes after administration of beta-lactam antibiotics $)^{45}$ or in possible cases of methicillin-resistant $S$. aureus (MRSA; patients hospitalized for longer than 3 days, transferred from another hospital, surgery for intracardiac implant or a vascular graft, or in hospitals with a high MRSA prevalence). Gram-negative coverage (using an aminoglycoside, usually gentamicin in the dose $<4 \mathrm{mg} / \mathrm{kg}$ body weight as a single dose) may be added when vancomycin is used as prophylaxis..$^{43,44}$

Intranasal mupirocin administration for all cardiac surgery procedures may be added. Two prospective and randomized control trials (RCTs) showed the benefit of mupirocin in reducing the incidence of DSWI ${ }^{46,47}$ Preoperative skin antiseptic preparations themselves can be considered since they may be useful, but the evidence is not well established yet. ${ }^{48}$

Implantable gentamicin-collagen sponges significantly reduce the risk of DSWI after cardiac surgery, although the extent of this benefit might be attenuated in patients receiving bilateral internal thoracic artery grafts. ${ }^{49,50}$ A recent metaanalysis of three large retrospective and one RCT has found a substantial reduction in the incidence of DSWI after cardiac surgery with the use of vancomycin paste administered topically to the sternal edge. ${ }^{51}$ Despite this evidence, concerns remain regarding persistent antibiotic levels may lead to emergence of resistant strains to these important antibiotics. 


\section{Empiric antimicrobial treatment}

Once DSWI is suspected in acutely unwell patients, systemic antimicrobial therapy should be immediately instituted after adequate sampling for microbiological investigations (tissue samples, blood, and eventually sputum). When a patient is septic, blood cultures should be obtained and empiric broadspectrum antibiotics should be administered immediately. The empirical antibiotic therapy should be directed against the most likely causative organisms, such as coagulase negative staphylococci, S. aureus (or MRSA when the MRSA prevalence in the hospital is high), and eventually Gramnegative, and anaerobic organisms. Treatment is generally started empirically, in order to control clinical sepsis, and especially to protect a newly inserted valve. If MRSA are rare, piperacillin/tazobactam (or imipenem or meropenem) is an adequate choice. In centers with a high prevalence of MRSA, vancomycin, teicoplanin, or daptomycin should be added. ${ }^{52}$

\section{Targeted antimicrobial treatment}

When results of microbiological cultures are available, targeted therapy should be initiated as soon as possible. Interpretation of microbiological results and susceptibility tests should be performed together with medical microbiologists and consultation with infectious disease specialists should be obtained for further guidance. Data on optimal antibiotic treatment in postoperative sternal osteomyelitis remain scarce, in particular, the duration and choice of antibiotics. Combination therapy of rifampicin and fluoroquinolones has been shown to be effective against staphylococci embedded in biofilms.$^{53}$ In a retrospective study, a rifampicin-containing antibiotic regimen was shown to improve the outcome of rifampicin-susceptible staphylococcal sternal osteomyelitis. ${ }^{54}$ Fosfomycin can be added to other antistaphylococcal antibiotic in treating staphylococcal infection, especially MRSA. Fosfomycin is shown to achieve clinically relevant concentrations in cortical bone, cancellous bone, and postosteomyelitis sequestra, ${ }^{55,56}$ and shown in the in vitro study to have synergism with beta-lactam antibiotics. ${ }^{57}$ Yet, it should not be used to replace rifampicin as an antibiofilm agent. ${ }^{58}$ Table 3 shows the choice of antibiotics according to the causing pathogen. Antifungal therapy can be administered in the absence of clinical improvement on a broad-spectrum antibiotic, even if no fungi are isolated.

Based on studies with periprosthetic joint infection, the authors recommend a total duration of therapy of 12 weeks, usually 2 weeks intravenously, followed by the oral route. ${ }^{59}$ If no foreign body such as cerclages is present, the treatment of bacterial osteitis can be shortened to 6 weeks. The initial intravenous therapy is given for 2 weeks since this is the

Table 3 Suggested targeted antibiotic therapy

\begin{tabular}{|c|c|c|c|}
\hline Microorganism & Antibiotic $^{a}$ & Dose $^{b}$ & Route \\
\hline \multicolumn{4}{|l|}{ Staphylococcus spp. } \\
\hline \multirow[t]{8}{*}{ Oxacillin/methicillin susceptible } & Flucloxacillinc & $4 \times 2 g$ & i.v. \\
\hline & (+/-Fosfomycin $)^{d}$ & $(3 \times 5 \mathrm{~g})$ & i.v. \\
\hline & for 2 weeks, followed by (ac & & \\
\hline & Rifampicine + & $2 \times 450 \mathrm{mg}$ & p.o. \\
\hline & - Levofloxacin or & $2 \times 500 \mathrm{mg}$ & p.o. \\
\hline & - Cotrimoxazole or & $3 \times 960 \mathrm{mg}$ & p.o. \\
\hline & - Doxycycline or & $2 \times 100 \mathrm{mg}$ & p.o. \\
\hline & - Fusidic acid & $3 \times 500 \mathrm{mg}$ & p.o. \\
\hline \multirow[t]{5}{*}{ Oxacillin/methicillin resistant } & Daptomycin or & $1 \times 8 \mathrm{mg} / \mathrm{kg}$ & i.v. \\
\hline & Vancomycin ${ }^{f}$ & $2 \times \lg$ & i.v. \\
\hline & $(+/ \text {-Fosfomycin })^{d}$ & $(3 \times 5 \mathrm{~g})$ & i.v. \\
\hline & for 2 weeks, followed by an & & \\
\hline & combination as above & & \\
\hline Rifampicin resistant & $\begin{array}{l}\text { Intravenous treatment acco } \\
\text { suppression for } \geq 1 \text { year }\end{array}$ & ks (as above), followed by long-term & \\
\hline \multicolumn{4}{|l|}{ Streptococcus spp. } \\
\hline & Penicillin $\mathrm{G}^{\mathrm{c}}$ or & $4 \times 5$ million $U$ & i.v. \\
\hline & Ceftriaxon & $1 \times 2 g$ & i.v. \\
\hline & for $2-3$ weeks, followed by & & \\
\hline & Amoxicillin or & $3 \times 1000 \mathrm{mg}$ & p.o. \\
\hline & Levofloxacin & $2 \times 500 \mathrm{mg}$ & p.o. \\
\hline
\end{tabular}


Table 3 (Continued)

\begin{tabular}{|c|c|c|c|}
\hline Microorganism & Antibiotic $^{a}$ & Dose $^{b}$ & Route \\
\hline \multicolumn{4}{|l|}{ Enterococcus spp. } \\
\hline \multirow[t]{4}{*}{ Penicillin susceptible } & Ampicillin + & $4 \times 2 \mathrm{~g}$ & i.v. \\
\hline & Gentamicing & $\mathrm{I} \times 240 \mathrm{mg}$ & i.v. \\
\hline & for 2-3 weeks, followed by & & \\
\hline & Amoxicillin & $3 \times 1000 \mathrm{mg}$ & p.o. \\
\hline \multirow[t]{6}{*}{ Penicillin resistant } & Vancomycin ${ }^{f}$ or & $2 \times \lg$ & i.v. \\
\hline & Daptomycin + & $\mathrm{I} \times 10 \mathrm{mg} / \mathrm{kg}$ & i.v. \\
\hline & Gentamicin ${ }^{g}$ & $\mathrm{I} \times 240 \mathrm{mg}$ & i.v. \\
\hline & (+/-Fosfomycin) & $3 \times 5 g$ & i.v. \\
\hline & for $2-4$ weeks, followed by & & \\
\hline & Linezolid (max. 4 weeks) & $2 \times 600 \mathrm{mg}$ & p.o. \\
\hline Vancomycin resistant & Individual; removal of the implant or lifelong su & cessary & \\
\hline \multicolumn{4}{|l|}{ Gram-negative } \\
\hline $\begin{array}{l}\text { Enterobacteriaceae (Escherichia } \\
\text { coli, Klebsiella, Enterobacter, etc.) }\end{array}$ & Ciprofloxacin ${ }^{\mathrm{h}}$ & $2 \times 750 \mathrm{mg}$ & p.o \\
\hline Non-fermenters (Pseudomonas & Piperacillin/tazobactam or meropenem or & $4 \times 4.5 \mathrm{~g} / 3 \times \mathrm{I} g$ & i.v. \\
\hline \multirow[t]{5}{*}{ aeruginosa, Acinetobacter spp.) } & Ceftazidime+ + & $3 \times 2 g$ & i.v. \\
\hline & Tobramycin & $\mathrm{I} \times 300 \mathrm{mg}$ & i.v. \\
\hline & (or gentamicin) & $\mathrm{I} \times 240 \mathrm{mg}$ & i.v. \\
\hline & for 2-3 weeks, followed by & & \\
\hline & Ciprofloxacin & $2 \times 750 \mathrm{mg}$ & p.o. \\
\hline Ciprofloxacin resistant & \multicolumn{3}{|c|}{$\begin{array}{l}\text { Depending on susceptibility: meropenem } 3 \times 1 \mathrm{~g} \text {, colistin } 3 \times 3 \text { million } \mathrm{U} \text {, and/or fosfomycin } 3 \times 5 \mathrm{~g} \text { i.v., } \\
\text { followed by oral long-term suppression }\end{array}$} \\
\hline \multicolumn{4}{|c|}{ - } \\
\hline Gram-positive (Cutibacterium, & Penicillin $\mathrm{G}^{\mathrm{c}}$ or & $4 \times 5$ million $U$ & i.v. \\
\hline Peptostreptococcus, Finegoldia & Ceftriaxon & $\mathrm{I} \times 2 \mathrm{~g}$ & i.v. \\
\hline \multirow[t]{4}{*}{ magna) } & for 2 weeks, followed by & & \\
\hline & Rifampicin $^{e}+$ & $2 \times 450 \mathrm{mg}$ & p.o. \\
\hline & - Levofloxacin or & $2 \times 500 \mathrm{mg}$ & p.o. \\
\hline & - Amoxicillin & $3 \times 1000 \mathrm{mg}$ & p.o. \\
\hline \multirow[t]{2}{*}{ Gram-negative (Bacteroides) } & Ampicillin/sulbactam ${ }^{c}$ for 2 weeks, followed by & $3 \times 3 g$ & i.v. \\
\hline & Metronidazol & $3 \times 400 \mathrm{mg}$ or $500 \mathrm{mg}$ & p.o. \\
\hline \multicolumn{4}{|l|}{ Candida spp. } \\
\hline \multirow[t]{4}{*}{ Fluconazole susceptible } & Caspofungini & $\mathrm{I} \times 70 \mathrm{mg}$ & i.v. \\
\hline & Anidulafungin & IXI00 mg (first day: 200 mg) & i.v. \\
\hline & for $1-2$ weeks, followed by & & \\
\hline & Fluconazole (suppression for $\geq \mathrm{I}$ year) & $\mathrm{I} \times 400 \mathrm{mg}$ & p.o. \\
\hline Fluconazole resistant & Individual (e.g., with voriconazole $2 \times 200$ mg p.o & of the implant or long-term sup & \\
\hline \multirow[t]{4}{*}{ Culture negative } & Ampicillin/sulbactam ${ }^{c}$ & $3 \times 3 \mathrm{~g}$ & i.v. \\
\hline & for 2 weeks, followed by & & \\
\hline & Rifampicin ${ }^{\mathrm{e}}+$ & $2 \times 450 \mathrm{mg}$ & p.o. \\
\hline & Levofloxacin & $2 \times 500 \mathrm{mg}$ & p.o. \\
\hline
\end{tabular}

Notes: aTotal duration of therapy: 6-12 weeks, usually 2 weeks intravenously, followed by oral route. 'Laboratory testing $2 \times$ weekly: leukocytes, CRP, creatinine/eGFR, liver enzymes (AST/SGOT and ALT/SGPT). Dose adjustment according to renal function and body weight ( $<40 />100 \mathrm{~kg})$. ${ }^{\mathrm{C}} \mathrm{Penicillin}$ allergy of NON-type I (e.g., skin rash): cefazolin $(3 \times 2 \mathrm{~g}$ i.v.). In case of anaphylaxis (= type I allergy such as Quincke's edema, bronchospasm, and anaphylactic shock) or cephalosporin allergy: vancomycin ( $2 \times \mathrm{I} g$ i.v.) or daptomycin ( $1 \times 8 \mathrm{mg} / \mathrm{kg}$ i.v.) Ampicillin/sulbactam is equivalent to amoxicillin/clavulanic acid $\left(3 \times 2.2 \mathrm{~g}\right.$ i.v.). ${ }^{\mathrm{P}}$ Fosfomycin can be added in treating Staphylococcal infection, especially MRSA, but it cannot replace rifampicin as an antibiofilm agent. ${ }^{58}$ eRifampicin is administered only if an implant is in situ. Add it to intravenous treatment as soon as wounds are dry and drains removed; in patients aged $>75$ years, rifampicin is reduced to $2 \times 300 \mathrm{mg}$ p.o. ${ }^{\mathrm{f}}$ Check vancomycin through concentration (take blood before next dose) at least IX/week; therapeutic range: $15-20 \mu \mathrm{g} / \mathrm{mL}$. ${ }^{8}$ Give only, if gentamicin $\mathrm{HL}$ is tested susceptible (consult the microbiologist). In gentamicin HL-resistant Enterococcus faecalis, gentamicin is exchanged with ceftriaxone $\left(\mathrm{I} \times 2 \mathrm{~g}\right.$ i.v.). ${ }^{\mathrm{h}}$ Add i.v. treatment (piperacillin/tazobactam $3 \times 4.5 \mathrm{~g}$ or ceftriaxone $\mathrm{I} \times 2 \mathrm{~g}$ or meropenem $3 \times \mathrm{I} \mathrm{g}$ i.v. $)$ in the first postoperative days (until wound is dry). 'After a loading dose of $70 \mathrm{mg}$ on day I, reduce the dose to $50 \mathrm{mg}$ in patients weighing $<80 \mathrm{~kg}$ from day 2 .

Abbreviations: ALT, alanine aminotransferase; AST, aspartate aminotransferase; CRP, C-reactive protein; eGFR, estimated glomerular filtration rate; HL, high level; i.v., intravenous; MRSA, methicillin-resistant S. aureus; p.o., per oral; SGOT, serum glutamic oxaloacetic transaminase; SGPT, serum glutamic pyruvic transaminase.

duration of culture incubation. During the treatment, laboratory testing twice weekly is adviced where leukocytes, CRP, renal function (creatinine/estimated glomerular filtration rate), and liver enzymes (aspartate aminotransferase/serum glutamic oxaloacetic transaminase and alanine aminotransferase/serum glutamic pyruvic transaminase) are determined. Dose adjustments should be made according to renal function and body weight $(<40 />100 \mathrm{~kg})$. 
After sternal closure, switch to oral antibiotics is recommended for a total duration of 6 weeks (if no foreign material is present) or 12 weeks (if any foreign material is present). An earlier switch is avoided to prevent the rapid emergence of resistance, whilst the bacterial load remains high in the open wound. Cerclage wires are removed whenever possible, to remove the existing biofilm and prevent future relapse. Although long-term follow-up was not available, patients had good hospital recovery with low mortality based on this antibiotic strategy.

\section{Conclusion}

DSWI can be treated with the combination of appropriate surgical technique and antibiotic therapy. The multidisciplinary approach where various medical specialties are involved will deliver the best results.

\section{Disclosure}

The authors report no conflicts of interest in this work.

\section{References}

1. Juhl AA, Koudahl V, Damsgaard TE. Deep sternal wound infection after open heart surgery - reconstructive options. Scand Cardiovasc J. 2012;46(5):254-261.

2. Kubota H, Miyata H, Motomura N, et al. Deep sternal wound infection after cardiac surgery. J Cardiothorac Surg. 2013;8(1):132.

3. De Feo M, Renzulli A, Ismeno G, et al. Variables predicting adverse outcome in patients with deep sternal wound infection. Ann Thorac Surg. 2001;71(1):324-331.

4. Wang FD, Chang CH. Risk factors of deep sternal wound infections in coronary artery bypass graft surgery. J Cardiovasc Surg (Torino). 2000;41(5):709-713.

5. Salehi Omran A, Karimi A, Ahmadi SH, et al. Superficial and deep sternal wound infection after more than 9000 coronary artery bypass graft $(\mathrm{CABG})$ : incidence, risk factors and mortality. BMC Infect Dis. 2007;7(1):112.

6. Force SD, Miller DL, Petersen R, et al. Incidence of deep sternal wound infections after tracheostomy in cardiac surgery patients. Ann Thorac Surg. 2005;80(2):618-622.

7. Ridderstolpe L, Gill H, Granfeldt H, Ahlfeldt H, Rutberg H. Superficial and deep sternal wound complications: incidence, risk factors and mortality. Eur J Cardiothorac Surg. 2001;20(6):1168-1175.

8. Sears ED, Wu L, Waljee JF, Momoh AO, Zhong L, Chung KC. The impact of deep sternal wound infection on mortality and resource utilization: a population-based study. World J Surg. 2016;40(11): 2673-2680.

9. Floros P, Sawhney R, Vrtik M, et al. Risk factors and management approach for deep sternal wound infection after cardiac surgery at a tertiary medical centre. Heart Lung Circ. 2011;20(11):712-717.

10. Ariyaratnam P, Bland M, Loubani M. Risk factors and mortality associated with deep sternal wound infections following coronary bypass surgery with or without concomitant procedures in a UK population: a basis for a new risk model? Interact Cardiovasc Thorac Surg. 2010;11(5):543-546.

11. Cutrell JB, Barros N, McBroom M, et al. Risk factors for deep sternal wound infection after cardiac surgery: influence of red blood cell transfusions and chronic infection. Am J Infect Control. 2016;44(11):1302-1309.
12. Sakamoto H, Fukuda I, Oosaka M, Nakata H. Risk factors and treatment of deep sternal wound infection after cardiac operation. Ann Thorac Cardiovasc Surg. 2003;9(4):226-232.

13. Parisian Mediastinitis Study Group. Risk factors for deep sternal wound infection after sternotomy: a prospective, multicenter study. J Thorac Cardiovasc Surg. 1996;111(6):1200-1207.

14. El Oakley RM, Wright JE. Postoperative mediastinitis: classification and management. Ann Thorac Surg. 1996;61(3):1030-1036.

15. Tegnell A, Arén C, Ohman L. Coagulase-negative staphylococci and sternal infections after cardiac operation. Ann Thorac Surg. 2000;69(4):1104-1119.

16. Horan TC, Gaynes RP, Martone WJ, Jarvis WR, Emori TG. CDC definitions of nosocomial surgical site infections, 1992: a modification of CDC definitions of surgical wound infections. Infect Control Hosp Epidemiol. 1992;13(10):606-608.

17. Horan TC, Andrus M, Dudeck MA. CDC/NHSN surveillance definition of healthcare-associated infection and criteria for specific types of infections in the acute care setting. Am J Infect Control. 2008;36(5):309-332.

18. Robicsek F. Postoperative sterno-mediastinitis. Am Surg. 2000;66(2):184-192.

19. Abu-OmarY, Kocher GJ, Bosco P, et al. European association for cardiothoracic surgery expert consensus statement on the prevention and management of mediastinitis. Eur J Cardiothorac Surg. 2017;51(1):10-29.

20. Chan M, Yusuf E, Giulieri S, et al. A retrospective study of deep sternal wound infections: clinical and microbiological characteristics, treatment, and risk factors for complications. Diagn Microbiol Infect Dis. 2016;84(3):261-265.

21. Friberg O, Svedjeholm R, Källman J, Söderquist B. Incidence, microbiological findings, and clinical presentation of sternal wound infections after cardiac surgery with and without local gentamicin prophylaxis. Eur J Clin Microbiol Infect Dis. 2007;26(2):91-97.

22. Bor DH, Rose RM, Modlin JF, Weintraub R, Friedland GH. Mediastinitis after cardiovascular surgery. Rev Infect Dis. 1983;5(5):885-897.

23. Abboud CS, Wey SB, Baltar VT. Risk factors for mediastinitis after cardiac surgery. Ann Thorac Surg. 2004;77(2):676-683.

24. Akman C, Kantarci F, Cetinkaya S. Imaging in mediastinitis: a systematic review based on aetiology. Clin Radiol. 2004;59(7):573-585.

25. Jolles H, Henry DA, Roberson JP, Cole TJ, Spratt JA. Mediastinitis following median sternotomy: CT findings. Radiology. 1996;201(2):463-466.

26. Read C, Branford OA, Verjee LS, Wood SH. PET-CT imaging in patients with chronic sternal wound infections prior to reconstructive surgery: a case series. J Plast Reconstr Aesthet Surg. 2015;68(8):1132-1137.

27. Chen LF, Arduino JM, Sheng S, et al. Epidemiology and outcome of major postoperative infections following cardiac surgery: risk factors and impact of pathogen type. Am J Infect Control. 2012;40(10):963-968.

28. Borger MA, Rao V, Weisel RD, et al. Deep sternal wound infection: risk factors and outcomes. Ann Thorac Surg. 1998;65(4):1050-1056.

29. Charbonneau H, Maillet JM, Faron M, et al. Mediastinitis due to Gramnegative bacteria is associated with increased mortality. Clin Microbiol Infect. 2014;20(3):197-202.

30. Gårdlund B, Bitkover CY, Vaage J. Postoperative mediastinitis in cardiac surgery - microbiology and pathogenesis. Eur J Cardiothorac Surg. 2002;21(5):825-830.

31. Chaudhuri A, Shekar K, Coulter C. Post-operative deep sternal wound infections: making an early microbiological diagnosis. Eur J Cardiothorac Surg. 2012;41(6):1304-1308.

32. Johnson B, Davis J, Sisneros M. Mediastinitis: could your case be a candidate for candida? Am J Case Rep. 2012;13:86-88

33. Cotogni P. Deep sternal wound infection after cardiac surgery: evidences and controversies. World J Crit Care Med. 2015;4(4):265-273.

34. Singh K, Anderson E, Harper JG. Overview and management of sternal wound infection. Semin Plast Surg. 2011;25(1):25-33.

35. Atkins BZ, Onaitis MW, Hutcheson KA, Kaye K, Petersen RP, Wolfe WG. Does method of sternal repair influence long-term outcome of postoperative mediastinitis? Am J Surg. 2011;202(5):565-567. 
36. Jones G, Jurkiewicz MJ, Bostwick J, et al. Management of the infected median sternotomy wound with muscle flaps. The Emory 20-year experience. Ann Surg. 1997;225(6):766-776.

37. Morykwas MJ, Argenta LC, Shelton-Brown EI, McGuirt W. Vacuumassisted closure: a new method for wound control and treatment: animal studies and basic foundation. Ann Plast Surg. 1997;38(6):553-562.

38. De Feo M, Vicchio M, Santè P, Cerasuolo F, Nappi G. Evolution in the treatment of mediastinitis: single-center experience. Asian Cardiovasc Thorac Ann. 2011;19(1):39-43.

39. Sjögren J, Gustafsson R, Nilsson J, Malmsjö M, Ingemansson R. Clinical outcome after poststernotomy mediastinitis: vacuum-assisted closure versus conventional treatment. Ann Thorac Surg. 2005;79(6):2049-2055.

40. Yusuf E, Jordan X, Clauss M, Borens O, Mäder M, Trampuz A. High bacterial load in negative pressure wound therapy (NPWT) foams used in the treatment of chronic wounds. Wound Repair Regen. 2013;21(5):677-681.

41. Berdajs DA, Trampuz A, Ferrari E, Ruchat P, Hurni M, von Segesser LK. Delayed primary versus late secondary wound closure in the treatment of postsurgical sternum osteomyelitis. Interact Cardiovasc Thorac Surg. 2011;12(6):914-918.

42. Yusuf E, Borens O. Prevention of intraoperative infection. In: Kates $\mathrm{S}$, Borens O, editors. Principles of Orthopedic Infection Management. Dubbendorf: AO Foundation; 2017.

43. Edwards FH, Engelman RM, Houck P, Shahian DM, Bridges CR; Society of Thoracic Surgeons. The Society of Thoracic Surgeons practice guideline series: antibiotic prophylaxis in cardiac surgery, part I: duration. Ann Thorac Surg. 2006;81(1):397-404.

44. Engelman R, Shahian D, Shemin R, et al; Workforce on Evidence-Based Medicine, Society of Thoracic Surgeons. The Society of Thoracic Surgeons practice guideline series: antibiotic prophylaxis in cardiac surgery, part II: antibiotic choice. Ann Thorac Surg. 2007;83(4):1569-1576.

45. Baldo BA, Pham NH. Drug Allergy: Clinical Aspects, Diagnosis, Mechanisms, Structure-Activity Relationships. Springer: Heidelberg; 2013.

46. Bode LG, Kluytmans JA, Wertheim HF, et al. Preventing surgical-site infections in nasal carriers of Staphylococcus aureus. N Engl J Med. 2010;362(1):9-17.

47. Cimochowski GE, Harostock MD, Brown R, Bernardi M, Alonzo N, Coyle K. Intranasal mupirocin reduces sternal wound infection after open heart surgery in diabetics and nondiabetics. Ann Thorac Surg. 2001;71(5):1572-1579.
48. Lazar HL, Salm T Vander, Engelman R, Orgill D, Gordon S. Prevention and management of sternal wound infections. JThorac Cardiovasc Surg. 2016;152(4):962-972.

49. Kowalewski M, Pawliszak W, Zaborowska K, et al. Gentamicin-collagen sponge reduces the risk of sternal wound infections after heart surgery: meta-analysis. J Thorac Cardiovasc Surg. 2015;149(6):1631-1640.

50. Birgand G, Radu C, Alkhoder S, et al. Does a gentamicin-impregnated collagen sponge reduce sternal wound infections in high-risk cardiac surgery patients? Interact Cardiovasc Thorac Surg. 2013;16(2): 134-141.

51. Lazar HL, Ketchedjian A, Haime M, Karlson K, Cabral H. Topical vancomycin in combination with perioperative antibiotics and tight glycemic control helps to eliminate sternal wound infections. J Thorac Cardiovasc Surg. 2014;148(3):1035-1040.

52. Combes A, Trouillet JL, Joly-Guillou ML, Chastre J, Gibert C. The impact of methicillin resistance on the outcome of poststernotomy mediastinitis due to Staphylococcus aureus. Clin Infect Dis. 2004;38(6):822-829.

53. Zimmerli W, TrampuzA, Ochsner PE. Prosthetic-joint infections. NEngl $J$ Med. 2004;351(16):1645-1654.

54. Khanlari B, Elzi L, Estermann L, et al. A rifampicin-containing antibiotic treatment improves outcome of staphylococcal deep sternal wound infections. J Antimicrob Chemother. 2010;65(8):1799-1806.

55. Schintler MV, Traunmüller F, Metzler J, et al. High fosfomycin concentrations in bone and peripheral soft tissue in diabetic patients presenting with bacterial foot infection. J Antimicrob Chemother. 2009;64(3):574-578.

56. Roussos N, Karageorgopoulos DE, Samonis G, Falagas ME. Clinical significance of the pharmacokinetic and pharmacodynamic characteristics of fosfomycin for the treatment of patients with systemic infections. Int J Antimicrob Agents. 2009;34(6):506-515.

57. Alvarez S, Jones M, Berk SL. In vitro activity of fosfomycin, alone and in combination, against methicillin-resistant Staphylococcus aureus. Antimicrob Agents Chemother. 1985;28(5):689-690.

58. Mihailescu R, Furustrand Tafin U, Corvec S, et al. High activity of fosfomycin and rifampin against methicillin-resistant Staphylococcus aureus biofilm in vitro and in an experimental foreign-body infection model. Antimicrob Agents Chemother. 2014;58(5):2547-2553.

59. Zimmerli W, TrampuzA, Ochsner PE. Prosthetic-joint infections. NEngl J Med. 2004;351:1645-1654.
Infection and Drug Resistance

\section{Publish your work in this journal}

Infection and Drug Resistance is an international, peer-reviewed openaccess journal that focuses on the optimal treatment of infection (bacterial, fungal and viral) and the development and institution of preventive strategies to minimize the development and spread of resistance. The journal is specifically concerned with the epidemiology of antibiotic

\section{Dovepress}

resistance and the mechanisms of resistance development and diffusion in both hospitals and the community. The manuscript management system is completely online and includes a very quick and fair peerreview system, which is all easy to use. Visit http://www.dovepress.com/ testimonials.php to read real quotes from published authors. 